\title{
Circular yellow sticky trap with black background enhances attraction of Frankliniella occidentalis (Pergande) (Thysanoptera: Thripidae)
}

\author{
Bishwo Prasad Mainali and Un Taek LiM* \\ School of Bioresource Sciences, Andong National University; Andong 760-749, Republic of Korea
}

(Received 26 January 2009; Accepted 30 October 2009)

\begin{abstract}
Yellow sticky flat traps were cut into six geometrical shapes (square, circle, semi-circle, diamond, triangle, and inverted triangle) to evaluate their attractiveness to Frankliniella occidentalis (Pergande) (Thysanoptera: Thripidae). The square was used as a standard to compare with other shapes in the laboratory. Circle was the most effective, attracting 2.7 and 1.5 times more thrips in choice and no-choice experiments, respectively. Four different background colors were also employed in the circular trap, and their efficacies were compared. In both choice and no-choice tests, the circular yellow sticky trap on a black background attracted a significantly higher number of thrips than on a yellow, blue, or green background. In addition, the higher ratio of a black background to yellow sticky foreground enhanced thrips' attraction in the choice test. Based on these results, the efficacy of circular yellow sticky traps $(5 \mathrm{~cm}$ diameter $)$ on a black background $(12 \mathrm{~cm}$ wide $\times 12 \mathrm{~cm}$ length) was compared to commercial yellow sticky traps $(5 \mathrm{~cm}$ wide $\times 8$ $\mathrm{cm}$ length) in a strawberry greenhouse. The modified trap attracted 2.3-21 times more $F$. occidentalis than the commercial yellow sticky trap. Therefore, the modification of yellow sticky flat traps to a circular shape on a black background would be a good addition to the thrips management program.
\end{abstract}

Key words: Western flower thrips; visual attraction; geometrical shape; color contrast; pull strategy

\section{INTRODUCTION}

Western flower thrips, Frankliniella occidentalis (Pergande) (Thysanoptera: Thripidae), is an important pest of many crops worldwide, including vegetables, fruits, and ornamentals. F. occidentalis has spread to most areas of Korea and Japan since it first appeared in Jeju Island in 1993 and Chiba and Saitama Prefectures in 1990, respectively (Hayase and Fukuda, 1991; Lee et al., 2001). Considerable research has been conducted to develop monitoring programs for $F$. occidentalis using colored sticky traps, which are widely used in greenhouses (Moffitt, 1964; Yudin et al., 1987; Vernon and Gillespie, 1990, 1995; Jacobson, 1997; Seo et al., 2006). F. occidentalis shows a phototactic response to yellow, blue, violet, and white colors with low ultraviolet content (Vernon and Gillespie, 1990; Matteson and Terry, 1992). However, based on electro-retinograms, Matteson et al. (1992) found only two peaks in photoreception occurring at $365 \mathrm{~nm}$ in the UV region and $540 \mathrm{~nm}$ in the green-yellow region. They suggested that $F$. occidentalis use peak sensitivity to green-yellow in long-range orientation to plants and then use the contrast within plants to find flowers (Antignus, 2000). Although there is no physiological evidence for a third photopigment that is sensitive to blue wavelengths, blue sticky traps have been found to catch more thrips (Matteson and Terry, 1992; Brødsgaard, 1993; Antignus, 2000). Nevertheless, most growers use yellow sticky traps because it is the most attractive color for other pests, including whiteflies and aphids (Jacobson, 1997; Lewis, 1997). Blumthal et al. (2005) suggested that yellow sticky traps may be more appropriate in sampling for $F$. occidentalis than blue sticky traps based on their study on flower color preference.

Insect vision may be governed by variables other than the wavelength of the visible spectrum reflected from an object (Prokopy and Owens, 1983; Vernon and Gillespie, 1995). Visual cues, includ-

* To whom correspondence should be addressed at: E-mail: utlim@andong.ac.kr DOI: 10.1303/aez.2010.207 
ing color, shape, architecture, size, contrast with background components, and the angle of orientation of host plant relative to the perceiving organism, are important for insects to locate host plant (Prokopy and Owens, 1983; Moreno et al., 1984; Mainali and Lim, 2008). Vernon and Gillespie (1995) investigated the response of thrips to different shapes, color contrasts, and background colors on three-dimensional traps, but did not find any improvement in trapping efficacy per unit area compared to flat traps. Hence they concluded that three-dimensional traps are not preferable to flat traps due to the higher cost of manufacture and difficulty in handling. However, few studies have been performed on the modification of the geometrical shape of flat sticky traps or on incorporation of the background using different colors to enhance trap efficacy. In this study, we examined the responses of $F$. occidentalis to different shapes of yellow sticky traps with or without a background to improve the rectangular yellow sticky traps that are generally used in integrated thrips management.

\section{MATERIALS AND METHODS}

Thrips rearing. Adult $F$. occidentalis were collected from a strawberry greenhouse located in Songchun, Andong, Korea in 2006. Adult thrips were reared on leaves of red kidney bean, Phaseolus vulgaris L. (Fabaceae), in plastic containers (24 $\mathrm{cm}$ wide $\times 17 \mathrm{~cm}$ length $\times 8 \mathrm{~cm}$ height), the lid of which had two holes (6 cm diameter) in the center covered with fine mesh fabric (196 mesh count; Saatilene Hitech, Zurich Co., Como, Italy). Eight excised stems of red kidney bean with cotyledonous leaves were rooted on water-soaked cotton, and water was added to the cotton as needed after daily examination. A mixture of pure honey and pollen of pine tree was streaked along the main vein of each leaf using a paint brush. The containers were kept in a growth chamber having three compartments, each with a 60 watt round fluorescent tube overhead. The environmental condition of the growth chamber was maintained at $28^{\circ} \mathrm{C}$ and a photoperiod of 16L8D. Thirty newly emerged adult thrips were transferred to a new plastic container with food sources for the reproduction of the next generations.

Geometrical shapes. Commercial yellow sticky traps (LBL Trading Co., Seoul, Korea) were cut into six different shapes (square, diamond, circle, inverted equilateral triangle, equilateral triangle, and semicircle) of the same surface area (36 $\left.\mathrm{cm}^{2}\right)$ and attached to a piece of black paper $(30 \mathrm{~cm}$ wide $\times 30 \mathrm{~cm}$ length). The square was used as the standard shape in pairwise comparisons. Fifty adult females of $F$. occidentalis were released on a kidney bean plant with cotyledonous leaves grown in a pot $(10 \mathrm{~cm}$ diameter $\times 12 \mathrm{~cm}$ height $)$ inside an acryl cage $(30 \mathrm{~cm}$ wide $\times 30 \mathrm{~cm}$ length $\times 30 \mathrm{~cm}$ height) for acclimatization. The cage was ventilated on three lateral sides and covered with a fine mesh screen to prevent thrips from escaping. After $2 \mathrm{~h}$, a square (standard shape) on black paper and one of the other shapes on black paper were mounted on opposite inside walls of the cage. All experiments were conducted inside the growth chamber $\left(28^{\circ} \mathrm{C}\right.$ and $16 \mathrm{~L} 8 \mathrm{D}$ photoperiod), and the overhead round fluorescent tube was placed $20 \mathrm{~cm}$ above the cages. The number of $F$. occidentalis on the sticky traps was recorded daily for $7 \mathrm{~d}$. Each experiment was replicated five times, and the position of the traps was alternated for each replication. No-choice tests for each type of sticky trap were also carried out under the same conditions as in the choice test.

Background colors. The effect of background color on thrips attraction was assessed using traps made in the laboratory. A sheet of yellow paper (color code: P09; Samwon Paper Ltd., Seoul) was cut into a circle $(10 \mathrm{~cm}$ diameter) and attached to the center of black, blue, green, or yellow paper $(17 \mathrm{~cm}$ wide $\times 17 \mathrm{~cm}$ length, color codes: P38, P35, P28, P09; Samwon Paper Ltd.) used as a background. The paper was then laminated using film (100 MIC; LamiAce Co., Kimpo, Korea), and a thin layer of Tanglefoot (The Tanglefoot Co., Grand Rapids, MI, USA) was applied to the yellow surface only. The relative preference for the different background color was assessed in pairwise comparisons with the black background according to the procedures described in the previous section. No-choice tests using the laboratory-made circular sticky trap on each background color were conducted under the same conditions.

Ratio of sticky area to background. We assessed if the relative size of the background affects the attractiveness of the circular sticky trap. Three different sizes of yellow circle $(7,10$, and $14 \mathrm{~cm}$ diameter, respectively) were attached to black paper 
(17 $\mathrm{cm}$ wide $\times 17 \mathrm{~cm}$ length) to make area ratios of $1: 7.5,1: 3.7$, and $1: 1.8$ (foreground: background). Comparisons were made for pairs of $1: 7.5$ versus $1: 1.8$ and $1: 7.5$ versus $1: 3.7$. The attraction of $F$. occidentalis was assessed daily for $7 \mathrm{~d}$ using the same experimental procedures as described in the previous section. No-choice tests were also carried out under the same conditions.

Greenhouse evaluation. The attractiveness of the modified yellow sticky trap was evaluated in a commercial strawberry greenhouse $(74 \mathrm{~m}$ length $\times$ $7.5 \mathrm{~m}$ wide) located in Songchun, Andong. Strawberry plants in the greenhouse were planted $35 \mathrm{~cm}$ apart in rows with $75 \mathrm{~cm}$ between rows in November 2006. During the experiment in 2007, strawberry plants were in flowering and fruiting stages. Comparisons were made between laboratory-designed yellow sticky circle $(5 \mathrm{~cm}$ diameter $)$ with a black background $(12 \mathrm{~cm}$ wide $\times 12 \mathrm{~cm}$ length) and commercial yellow sticky traps $(5 \mathrm{~cm}$ wide $\times 8 \mathrm{~cm}$ length). The greenhouse was divided into 35 plots, each of $1 \mathrm{~m} \times 10 \mathrm{~m}$. Among them, 20 plots were randomly selected, and the yellow sticky circles with a background and the commercial yellow sticky traps were installed just above plant height in the center of each plot. The distance between traps was $1.2 \mathrm{~m}$, and the traps were facing each other in random directions. The traps were all collected after $72 \mathrm{~h}$ and brought into the laboratory to identify the adult thrips, which were extracted from the sticky surface using xylene and ethylene glycol, and identified under a stereomicroscope according to Mound and Kibby (1998). The numbers of F. occidentalis and $F$. intonsa (Trybom) were counted and compared between two types of traps. Experiments were replicated twice on April 18-21 and May 12-15, 2007.

Reflectance patterns of the modified yellow sticky trap and the commercial yellow sticky trap were measured at $10 \mathrm{~nm}$ intervals from 400 to 700 $\mathrm{nm}$ using a spectrum color meter (JS555; Minolta, Tokyo, Japan).

Statistical analyses. Data for choice tests in the laboratory and comparison tests in the strawberry greenhouse were analyzed using a paired $t$-test. Results from no-choice tests were subjected to Kruskal-Wallis single factor analysis of variance by rank and, if significance was detected, multiple comparison was conducted using the Dunn test (Zar, 2009).

\section{RESULTS}

\section{Geometrical shapes}

The circular shape was the most effective and attracted 2.7 times more female $F$. occidentalis $(t=14.230, \mathrm{df}=4, p<0.001)$ in choice experiments than the standard square shape. Triangles also captured significantly higher number of thrips (1.5 times) than the standard shape $(t=6.147, \mathrm{df}=4$, $p=0.004$ ) (Fig. 1A); however, in no-choice tests, only the circle captured 1.5 times more thrips than the standard shape, and the diamond was the least attractive $\left(H_{\mathrm{c}}=23.112, \mathrm{df}=5, p<0.001\right)$ (Fig. 1B).

\section{Background colors}

There was a significant effect of background color on the attraction of female F. occidentalis. In the choice test, the sticky circle on the black background captured 1.4, 1.8, and 2.6 times more female thrips than on blue $(t=5.055, \mathrm{df}=4, p=$
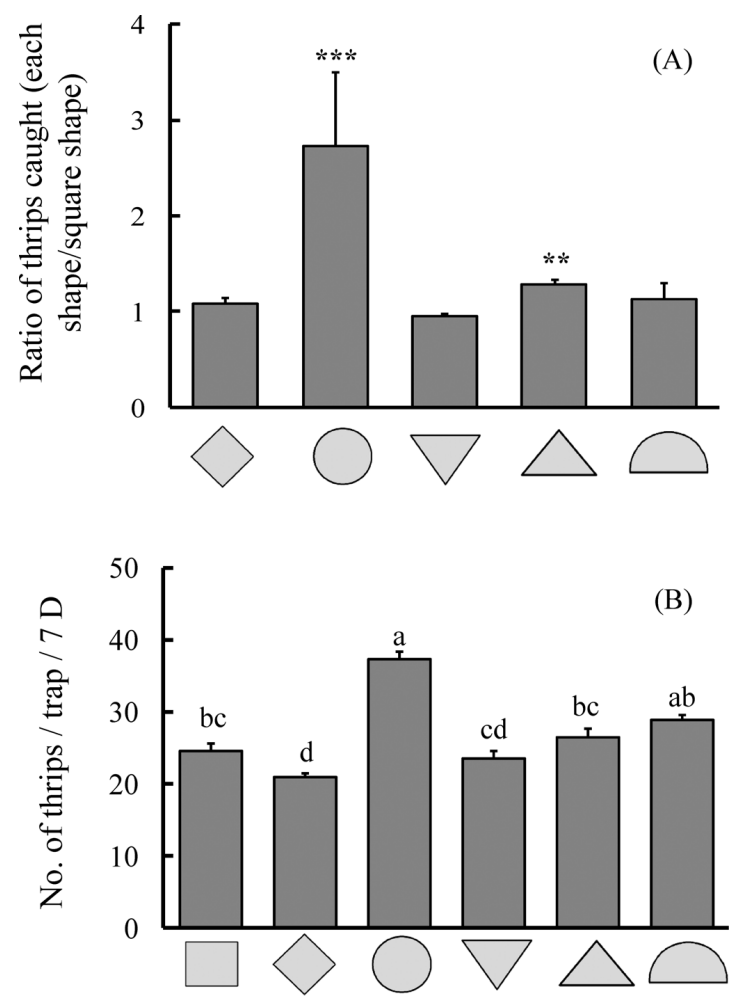

Fig. 1. Ratio ( $\pm \mathrm{SE})$ of female F. occidentalis captured on various shapes of yellow sticky traps to the number of thrips captured by square sticky trap in choice tests (A), and the number $( \pm \mathrm{SE})$ of thrips attracted per trap in no-choice tests (B). $* 0.01<p \leq 0.05, * * 0.001<p \leq 0.01$, and $* * * p \leq 0.001$ from a paired $t$-test. Values with different letters are significantly different from the Dunn test. See text for statistics. 


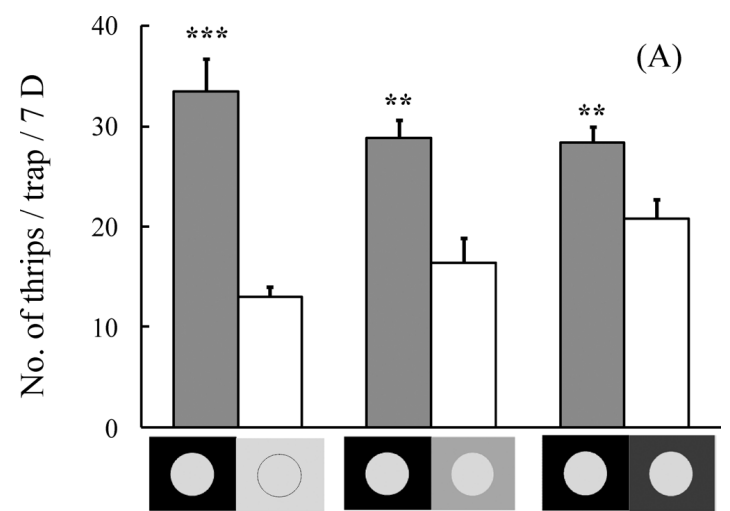

(Black : Yellow)(Black : Green) (Black : Blue)

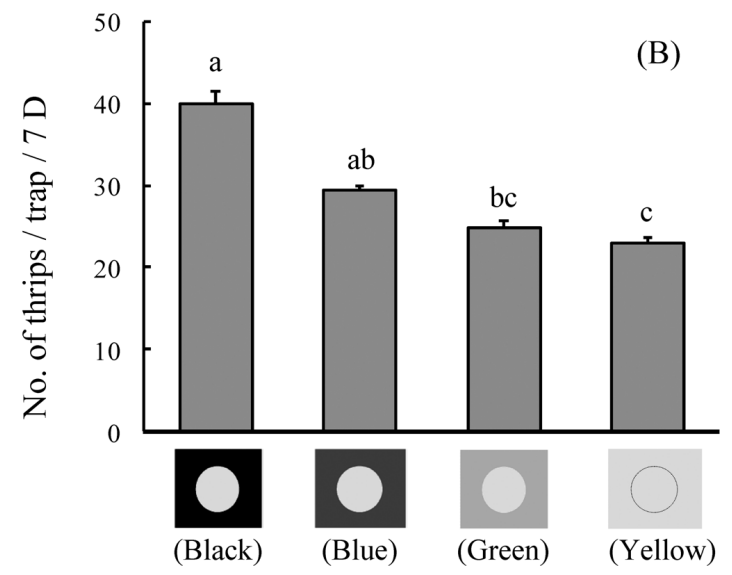

Fig. 2. Number $( \pm \mathrm{SE})$ of female $F$. occidentalis captured on yellow sticky circle with a different background color in choice (A) and no-choice tests (B). $* 0.01<p \leq 0.05$, $* * 0.001<p \leq 0.01$, and $* * * p \leq 0.001$ from a paired $t$-test. Values with different letters are significantly different from the Dunn test.

$0.007)$, green $(t=5.167, \mathrm{df}=4, p=0.007)$, and yellow backgrounds $(t=25.110, \mathrm{df}=4, p<0.001)$, respectively (Fig. 2A). Similarly, in no-choice tests, the sticky circle on the black background was better to attract thrips $\left(H_{\mathrm{c}}=16.707, \mathrm{df}=3, p<0.001\right)$ (Fig. 2B).

\section{Ratio of sticky area to background}

In the choice test, when we analyzed the number of the thrips per trap, the sticky circle with a ratio of $1: 7.5$ caught $1.9(t=8.375, \mathrm{df}=4, p=0.001)$ and $1.4(t=5.887, \mathrm{df}=4, p=0.004)$ times more thrips than sticky circles with ratios of $1: 3.7$ and $1: 1.8$, respectively (Fig. 3A). However, there was no significant difference in the number of thrips per trap among treatments in no-choice tests $\left(H_{\mathrm{c}}=5.188\right.$, $\mathrm{df}=2, p=0.054)$ (Fig. 3B).
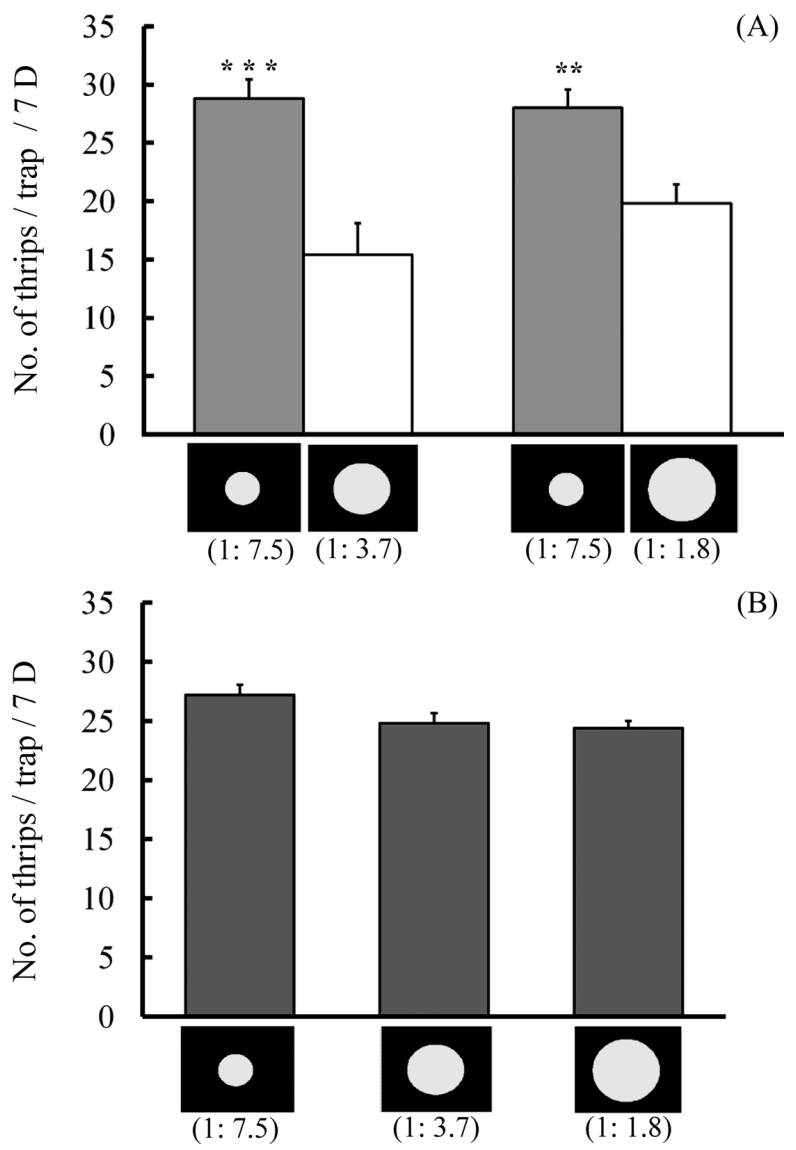

Fig. 3. Number $( \pm \mathrm{SE})$ of female $F$. occidentalis per trap, captured on yellow sticky circles with different ratios of foreground to background area in choice (A) and no-choice tests (B). $* 0.01<p \leq 0.05, * * 0.001<p \leq 0.01$, and $* * * p \leq 0.001$ from a paired $t$-test.

\section{Greenhouse evaluation}

Reflection patterns of both the modified yellow sticky trap and the commercial trap are presented in Fig. 4. Both traps with similar spectral reflectance characteristics began to peak at $500 \mathrm{~nm}$ and leveled off at $550 \mathrm{~nm}$.

Figure 5 shows the numbers of adult $F$. occidentalis and $F$. intonsa (both sexes combined) caught on the two types of traps installed in a greenhouse. In the first trial, when the population of thrips was low in the greenhouse, the yellow sticky circle with a black background captured 21 times more F. occidentalis than the commercial yellow sticky trap $(t=4.951, \mathrm{df}=19, p<0.001)$ (Fig. 5A). In the second trial when the thrips population was increasing, the modified trap was 2.3 times more effective in attracting $F$. occidentalis $(t=4.729, \mathrm{df}=19$, $p<0.001)$. The modified trap also attracted a higher 


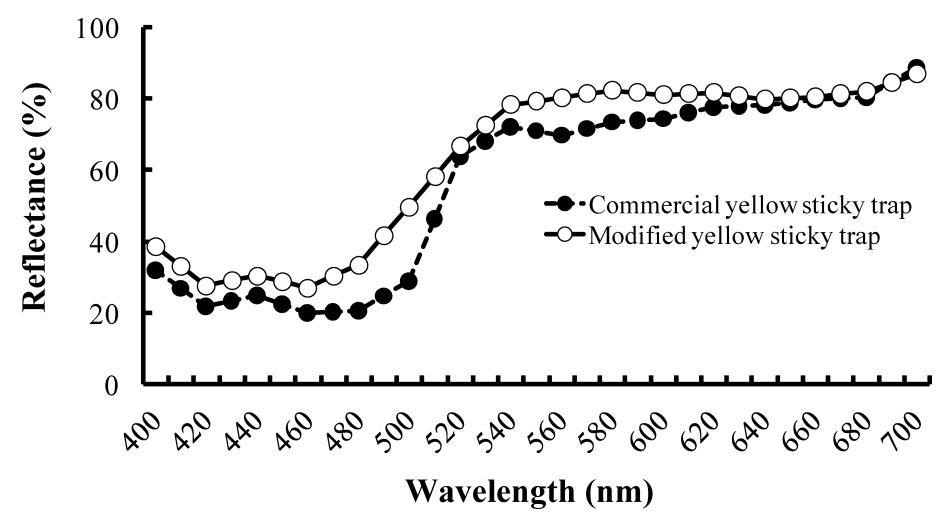

Fig. 4. Spectral reflectance of the modified circular yellow sticky traps and commercial yellow sticky traps measured by a spectrum color meter.

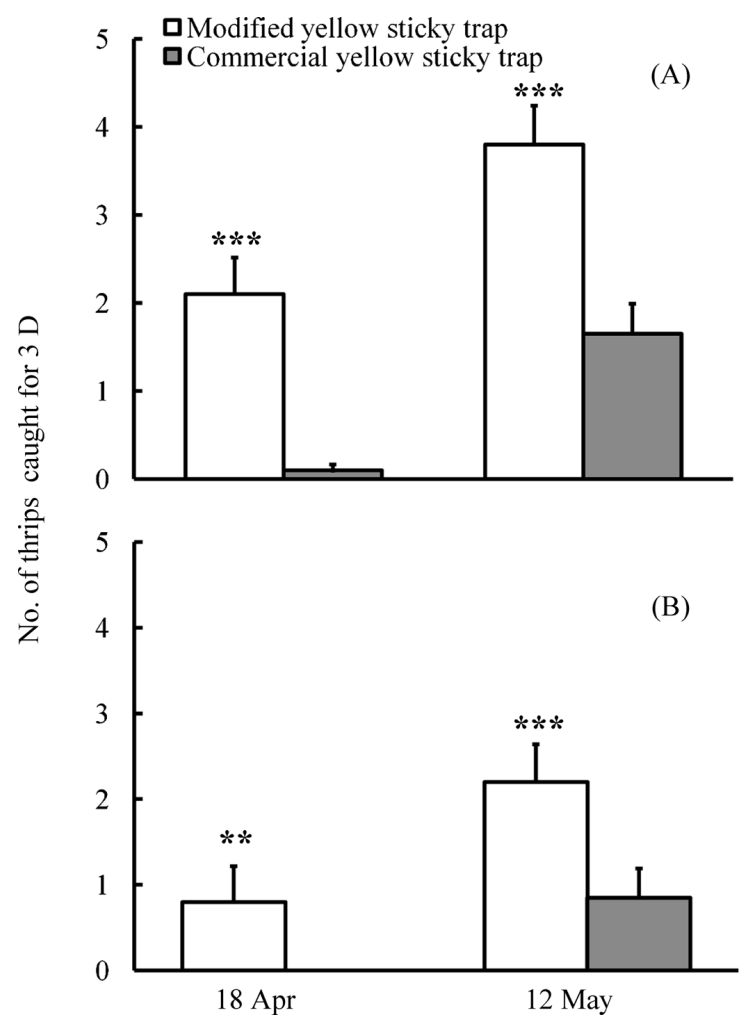

Fig. 5. Number $( \pm \mathrm{SE})$ of F. occidentalis (A) and F. intonsa (B) captured on yellow sticky circles with a black background and on commercial yellow sticky traps in a strawberry greenhouse. $* 0.01<p \leq 0.05, * * 0.001<p \leq 0.01$, and $* * * p \leq$ 0.001 from a paired $t$-test.

number of $F$. intonsa on both sampling dates $(t=3.107, \mathrm{df}=19, p=0.006$ for 18 Apr.; $t=4.133$, $\mathrm{df}=19, p<0.001$ for 12 May) (Fig. 5B).

\section{DISCUSSION}

The results of this study indicated that female $F$. occidentalis preferred the circular shape to other shapes in both choice and no-choice tests (Fig. 1). The circular shape may give the impression of a flower to anthophilous thrips, which often orients to flowers for feeding, mating, and/or oviposition (Terry, 1997; Gerin et al., 1999; Buitenhuis and Shipp, 2006; Mainali and Lim, 2008). In a similar study, Moreno et al. (1984) found higher numbers of Scirtothrips citri (Moulton) attracted to triangular, rectangular, or elliptical traps than square or circular traps. They suggested that the triangle, rectangle, and ellipse would look like tender leaves to thrips, whereas squares and circles are more like mature fruits. S. citri must find succulent young growth where nitrogen content is high with spring fruit where it can feed and lay eggs (Moreno et al., 1984). Attraction of F. occidentalis to different shapes and/or colors was also studied by Vernon and Gillespie (1995) using three-dimensional traps. They found a higher number of thrips captured on cylindrical traps compared to other three-dimensional traps, but it was not significantly higher than a flat trap. Hata et al. (1991) also found a specific shape preference of melon thrips, Thrips palmi Karny, from a study on the recognition of different flower shapes of 21 Dendrobium cultivars and the bamboo orchid. In other insects, such as honeybee, floral shape is a visual cue that pollinators use to discriminate competing flower species (Hempel de Ibarra and Giurfa, 2003).

The yellow sticky trap with a yellow, green, or blue background was less attractive to F. occidentalis than traps with a black background (Fig. 2). Vernon and Gillespie (1995) also reported that high contrast background colors, such as blue and vio- 
let, to the yellow sticky trap captured a significantly higher number of $F$. occidentalis than lowcontrast background colors. The effectiveness of traps was generally reduced by a background of the same color (Vernon and Gillespie, 1995); thus, the trap with a yellow background was the least effective in both choice and no-choice tests (Fig. 2). Unlike the background frame that was used along with the three-dimensional traps (but was not in contact with the shape) in their study, we used a flat background on which yellow cards were attached. Because the sticky trap with a larger background area caught more thrips per sticky trap (Fig. 3 ), the black background may help the insect to perceive reflectance with minimum interception from the other source of reflectance. This explanation also supports the findings that a white cup trap is more attractive to $F$. occidentalis than yellow, blue, or other colored cup traps in a green-colored lettuce field (Yudin et al., 1987). Competition from the surrounding background and differing UV reflectance of trap pigments made the trap less prominent (Lewis, 1997). Increased attraction to traps with a dark background was also reported in other insects. Döring et al. (2004) tested water pan traps placed on colored plastic sheets and found higher numbers of alate aphids caught in traps with a dark background (e.g., black, dark green). Although the effect of background color can be tested in a variety of color combinations, we focused on a yellow trap as it is popularly being used to monitor or manage various insect pests in protected cultures (Jacobson, 1997).

Greenhouse experiments further support the results of laboratory studies. The numbers of both $F$. occidentalis and $F$. intonsa caught by the modified trap were higher than those by the commercial sticky trap (Fig. 5). A significant increase in thrips number was found in a relatively short period of time after the first sampling date. This may have been due to the introduction of a thrips population from outside vegetation to the greenhouse whose windows were kept open more frequently as temperature rose.

Because the effect of the modified trap with a larger black background was significant only in the choice test, but was not significant in the no-choice test (Fig. 3), an argument can be made on its efficacy compared to other ordinary sticky traps if nochoice is provided. However, there is probably a choice between host plants and sticky traps placed in greenhouses; thus, the modified trap with a larger background would still capture a higher number of thrips than other ordinary sticky traps, as presented in Fig. 2.

Increased capture by modified sticky traps would reduce crop damage and prophylactic application of insecticides (Samways, 1986). The modified trap can also be incorporated into integrated pest management tactics as a mass-trapping device for F. occidentalis in greenhouses. Furthermore, the trap would be beneficial in capturing other greenhouse pests, such as whitefly, fungus gnats, shoreflies, and winged aphids. Finally, the exploitation of attractive visual cues as in this study and the integration of olfactory stimulants, such as anisaldehyde and aggregation pheromone (Lewis, 1997; Terry, 1997; Hamilton et al., 2005), would provide a new direction in managing thrips pests as a component of the pull strategy in greenhouses.

\section{ACKNOWLEDGMENTS}

This work was supported by the Korea Research Foundation Grant funded by the Korean Government (MOEHRD) (KRF2007-331-F00010). Bishwo P. Mainali was supported by the 2nd Stage BK21 program of the Ministry of Education, Science, and Technology, Republic of Korea.

\section{REFERENCES}

Antignus, Y. (2000) Manipulation of wavelength-dependent behaviour of insects: an IPM tool to impede insects and restrict epidemics of insect-borne viruses. Virus Res. 71: 213-220.

Blumthal, M. R., R. A. Cloyd, L. A. Spomer and D. F. Warnock (2005) Flower color preferences of western flower thrips. HortTechnology 15: 846-853.

Brødsgaard, H. F. (1993) Monitoring thrips in glasshouse pot plant crops by means of blue sticky traps. IOBC/WPRS 16: 29-32.

Buitenhuis, R. and J. L. Shipp (2006) Factors influencing the use of trap plants for the control of Frankliniella occidentalis (Thysanoptera: Thripidae) on greenhouse potted chrysanthemum. Environ. Entomol. 35: 1411-1416.

Döring, T. F., S. M. Kirchner, S. Kühne and H. Saucke (2004) Response of alate aphids to green targets on coloured backgrounds. Entomol. Exp. Appl. 113: 53-61.

Gerin, C., Th. Hance and G. Van Impe (1999) Impact of flowers on the demography of western flower thrips Frankliniella occidentalis (Thysan., Thripidae). J. Appl. Entomol. 123: 569-574.

Hamilton, J. G. C., D. R. Hall and W. D. J. Kirk (2005) Identification of a male-produced aggregation pheromone in the western flower thrips Frankliniella occidentalis. $J$. Chem. Ecol. 31: 1369-1379.

Hata, T. Y., A. H. Hara and J. D. Hansen (1991) Feeding 
preference of melon thrips on orchids in Hawaii. HortScience 26: 1294-1295.

Hayase, T. and H. Fukuda (1991) Occurrence of the western flower thrips, Frankliniella occidentalis (Pergande), on the cyclamen and its identification. Plant Prot. 45: 59-61 (in Japanese).

Hempel de Ibarra, N. and M. Giurfa (2003) Discrimination of closed coloured shapes by honeybees requires only contrast to the long wavelength receptor type. Anim. Behav. 66: 903-910.

Jacobson, R. T. (1997) Integrated pest management (IPM) in glasshouses. In Thrips as Crop Pests (T. Lewis, ed.). CAB International, Cambridge, pp. 639-666.

Lee, G. S., J. H. Lee, S. H. Kang and K. S. Woo (2001) Thrips species (Thysanoptera: Thripidae) in winter season and their vernal activities on Jeju island, Korea. J. AsiaPacific Entomol. 4: 115-122.

Lewis, T. (1997) Field and laboratory techniques. In Thrips as Crop Pests (T. Lewis, ed.). CAB International, Cambridge, pp. 435-476.

Mainali, B. P. and U. T. Lim (2008) Evaluation of chrysanthemum flower model trap to attract two Frankliniella thrips (Thysanoptera: Thripidae). J. Asia-Pacific Entomol. 11: 171-174.

Matteson, N. A. and L. I. Terry (1992) Response to color by male and female Frankliniella occidentalis during swarming and non-swarming behavior. Entomol. Exp. Appl. 63: 187-201.

Matteson, N., I. Terry, A. Ascolichristensen and C. Gilbert (1992) Spectral efficiency of the western flower thrips, Frankliniella occidentalis. J. Ins. Physiol. 38: 453-459.

Moffitt, H. R. (1964) A color preference of the western flower thrips, Frankliniella occidentalis. J. Econ. Entomol. 57: 604-605.

Moreno, D. S., W. A. Gregory and L. K. Tanigoshi (1984) Flight response of Aphytis melinus (Hymenoptera: Aphelinidae) and Scirtothrips citri (Thysanoptera: Thripidae) to trap color, size, and shape. Environ. Entomol. 13: 935-940.

Mound, L. A. and G. Kibby (1998) Thysanoptera, an Identification Guide. 2nd ed. CAB International, Wallingford, United Kingdom. 76 pp.

Prokopy, R. J. and E. D. Owens (1983) Visual detection of plants by herbivorous insects. Annu. Rev. Entomol. 28: 337-364.

Samways, M. J. (1986) Spatial distribution of Scirtothrips aurantii Fuare (Thysanoptera: Thripidae) and threshold level for one percent damage on citrus fruit based on trapping with fluorescent yellow sticky traps. Bull. Entomol. Res. 76: 649-659.

Seo, M. J., S. J. Kim, E. J. Kang, K. M. Kang, Y. M. Yu, M. H. Nam, S. G. Jeong and Y. N. Youn (2006) Attraction of the garden thrips, Frankliniella intonsa (Thysanoptera: Thripidae) to colored sticky cards in a Nonsan strawberry greenhouse. Kor. J. Appl. Entomol. 45: 37-43 (in Korean with English summary).

Terry, L. I. (1997) Host selection communication and reproductive behaviour. In Thrips as Crop Pests (T. Lewis, ed.). CAB International, Cambridge, pp. 65-118.

Vernon, R. S. and D. R. Gillespie (1990) Spectral responsiveness of Frankliniella occidentalis (Thysanoptera, Thripidae) determined by trap catches in greenhouses. Environ. Entomol. 19: 1229-1241.

Vernon, R. S. and D. R. Gillespie (1995) Influence of trap shape, size, and background color on captures of Frankliniella occidentalis (Thysanoptera: Thripidae) in a cucumber greenhouse. J. Econ. Entomol. 88: 288-293.

Yudin, L. S., I. Mitchell and J. J. Cho (1987) Color preference of thrips (Thysanoptera: Thripidae) with reference to aphids (Homoptera: Aphididae) and leafminers in Hawaiian lettuce farms. J. Econ. Entomol. 80: 51-55.

Zar, J. H. (2009) Biostatistical Analysis. 5th ed. Prentice Hall, Upper Saddle River, NJ. 944 pp. 